
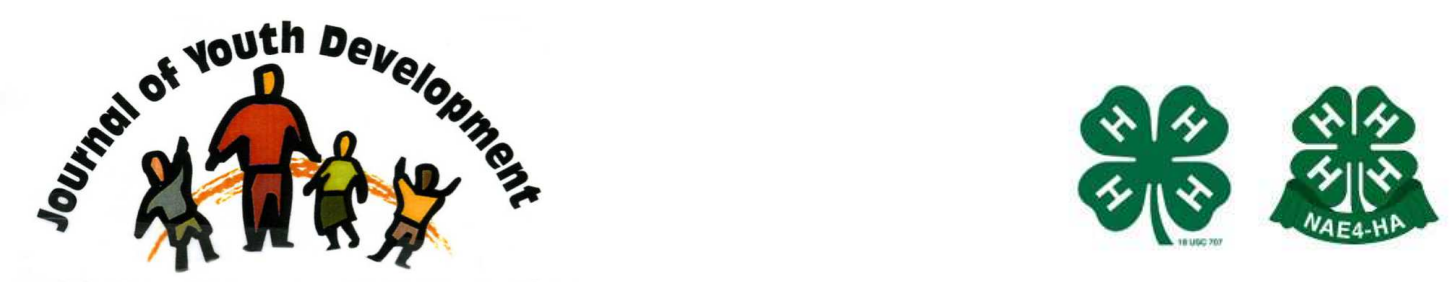

Bridging Research \& Practice

\title{
The Impact of Parental Involvement on a Structured Youth Program Experience: A Qualitative Inquiry
}

Mat D. Duerden

Brigham Young University

Provo, UT

duerden@byu.edu

Peter A. Witt

Texas A\&M University

Christopher J. Harrist

Texas A\&M University 


\title{
JOURNAL OF YOUTH DEVELOPMENT \\ bridging research and practice

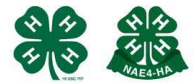

Volume 8, Number 3, Winter 2013

Article 130803RS001

\section{The Impact of Parental Involvement on a Structured Youth Program Experience: A Qualitative Inquiry}

\author{
Mat D. Duerden \\ Brigham Young University \\ Peter A. Witt \& Christopher J. Harrist \\ Texas A\&M University
}

\begin{abstract}
Parental involvement is an often proposed, but rarely researched, key element of youth programs. Questions remain regarding the impact of parental involvement on program processes and outcomes. Qualitative data were collected over a one-year period with youth participants $(n=46)$, parents $(n=26)$, and teachers $(n=5)$ associated with an international immersion/service learning program for adolescents. Three main research questions guided the data analysis: (1) what role does parental involvement play in the youths' experience in the program; (2) how does parental involvement in the program influence the parent/child relationship; and (3) what role does parental involvement play in terms of the program's long-term impact on the youth participants? Findings suggest a relationship between parental involvement in youth programs and improved parent/child communication, bonding, and perceptions of one another. Findings also suggest that having a common ground experience prolonged the experience's positive post-participation effects.
\end{abstract}

\section{Introduction}

Positive youth development literature promotes increasing competencies and providing adolescents access to key developmental assets (Witt, \& Caldwell, 2005). Two key assets include positive youth/adult interactions (including those with parents) and participation in structured leisure activities. A wide range of literature highlights the impact of parents on youth development. For example, literature suggests parental influence on youth extends beyond the home and impacts adolescents' behavior (Baumrind, 1991), the peers they choose (Brown, 
Mounts, Lamborn, \& Steinberg, 1993; Ladd, \& Le Sieur, 1995), their leisure time activities (Green \& Chalip, 1998; Outley \& Floyd, 2002), and their academic performance (Woolley, \& Grogan-Kaylor, 2006). Evidence related to the ability of structured leisure activities (i.e., youth programs) to serve as developmental contexts is also well documented (e.g., Larson, 2000; Mahoney, \& Stattin, 2000). Consequently, it would seem a promising strategy to involve parents where appropriate in the programs frequented by their children.

Indeed, parental involvement is a common best practice suggestion for youth program providers and educators and a noted characteristic of successful youth programs (Catalano, Berglund, Ryan, Lonczak, \& Hawkins, 2004; Eccles, \& Harold, 1993; Trotman, 2001). Although parental involvement appears to be an effective component of youth development programs, it is often not easily facilitated for a number of reasons. First, while parents may be a positive addition to some programs, the opportunity for negative impact may be just as real, depending on the parents and the nature of their involvement. Some practitioners may hesitate to involve parents due to previous negative experiences. Second, while involving parents appears efficacious in theory, in practice it is often more difficult. Finally, some practitioners may value opportunities to work and interact with youth in program settings free from the influence of parents. An increased understanding of the underlying mechanisms that are put into action when parents become involved in youth programs might make it easier for practitioners to promote parental involvement.

Unfortunately, there is a lack of research regarding the processes that occur when parents engage in youth programs. Therefore, the purpose of this study was to qualitatively investigate the role of parental involvement in a structured youth program, in this case an international immersion/service learning program. The study's findings provide insights into what happens when parents become involved in their children's out-of-school time programs. A qualitative approach was deemed appropriate for the study as it enabled the individuals most directly connected with these processes (e.g., youth participants and their parents) to inform researchers regarding key concepts and relationships (Auerbach, \& Silverstein, 2003). It was also hoped the study could identify key parental involvement processes occurring within the observed program in order to facilitate future research with more representative samples.

\section{Literature Review}

\section{Parental Involvement}

The ability of adults to positively contribute to the healthy development of youth is supported by research from a variety of disciplines. Prevention and resiliency researchers have identified positive adult relationships as a key protective factor against a variety of risks (Benard, 1991; Coie, et al., 1993). Positive youth development advocates promote such relationships as key assets associated with youths' successful navigation of adolescence (Scales, Benson, Leffert, \& Blyth, 2000). The focus of these recommendations, especially within youth program contexts, is often on the role of non-parental adults. For example, there is an established body of research related to the impact of coaching (Pelletier, Fortier, Vallerand, \& Briere, 2001; Smoll, Smith, Barnett, \& Everett, 1993) and mentoring relationships (DuBois, Holloway, Valentine, \& Cooper, 2002; Grossman, \& Johnson, 1999) with adolescents.

While research related to parents' direct involvement in youth program contexts remains sparse, studies have been conducted related to the influence that parents have on the types of leisure activities in which their children participate. For example, middle school-age youth whose parents more closely monitor their behavior and activities were found to participate in 
lower levels of substance abuse than non-monitored youth (Caldwell, \& Darling, 1999). Youth also appear to adopt parental participation patterns; for example, findings show that school-age youth (5-17 years) are more likely to become involved in the community and in extracurricular activities if their parents are involved in the community (Coulton, \& Irwin, 2009) and if their parents support and encourage their child's participation (Fletcher, Elder, \& Mekos, 2000). While such findings provide insights related to parents' indirect involvement in their children's leisure, research is needed to understand what happens when parents directly participate in their children's structured leisure experiences. Fortunately, research exists regarding the direct involvement in some other non-leisure and leisure contexts, which provides insights pertinent to this study's focus.

School. In educational circles, teachers and administrators have long identified strengthening parental participation as an issue that should receive the highest public education policy priority (U.S. Department of Education, 1994). Extant research overwhelmingly demonstrates that parental involvement in children's learning is positively related to achievement (Cotton, \& Wikelund, 2001). Findings from a meta-analysis of 52 studies on this topic indicate that parental involvement positively impacted academic achievement among urban secondary students across ethnic groups (Jeynes, 2007). Relationships that develop between parents and teachers have also been found to impact elementary age-students' classroom engagement and academic achievement (Hughes, \& Kwok, 2007), and positive parental school involvement has been linked to lower levels of problem behaviors for middle and high school students (Hill, et al., 2004) and increased academic achievement among 8- to 12-year-old students with ADHD (Rogers, Wiener, Marton, \& Tannock, 2009). Together these findings make a case for the impact parents can have on their children's overall academic experience if they become positively involved with school. The question remains whether or not the same degree of positive benefits is associated with parental involvement in out-of-school time contexts.

Youth sports. Youth sports represent an out-of-school time setting that has received some attention related to parental involvement. While research in this area is not extensive, most who have explored parental involvement in youth sports view positive support as fundamental to children's participation and success (Wylleman, DeKnop, Ewing, \& Cummings, 2000). For example, research looking at the impact of parental support on middle school-age tennis players found that youth who felt their parents supported their involvement reported higher levels of enjoyment and felt more attached to tennis than less supported youth (Hoyle \& Leff, 1997). Parents' encouragement of and commitment to their children's ( $M=8$ years old) participation in youth soccer has also been shown to positively relate to youths' perceptions of enjoyment, skill, and continued involvement in the sport (Green, \& Chalip, 1997).

Family recreation. Family recreation, another out-of-school time context, is an especially powerful setting for parents to interact with and influence their children. Qualitative findings regarding parents' perception of family leisure reveal that those parents interviewed felt family leisure should be purposive (Shaw, \& Dawson, 2001). In other words, family leisure was a prime opportunity to teach principles and promote the development of desired characteristics. Research findings support the efficacy of joint family leisure activities to promote positive functioning (Zabriskie, \& McCormick, 2001). For example, families who participated in a challenging outdoor recreation program experienced improved levels of family communication and problem solving efficacy (Huff, Widmer, McCoy, \& Hill, 2003; Wells, Widmer, \& McCoy, 2004). 
Interest development represents another potential outcome of family recreation. Research indicates that adolescents identified as interested in the world around them (i.e., open to new activities, fascinated, apt to explore, etc.) score higher on measures of self-esteem, locus of control, and optimism than adolescents identified as being bored (Hunter, \& Csikszentmihalyi, 2003). Interest is also an important concept because interested youth are more likely to explore the world around them, and this process of exploration is one of the main forces associated with identity formation (Marcia, 1980; Schmitt-Rodermund, \& Vondracek, 1999). SchmittRodermund and Vondracek's (1999) research indicates that adolescents who were actively engaged in a wider variety of activities as children are more likely to be active explorers during adolescence. They additionally note that parental involvement in these childhood activities had a strong positive impact on later adolescent exploration and identity development. In summary, parents who both expose their children to a breadth of different activities and also participate with their children in these activities are more likely to have interested adolescents who actively explore the world around them.

\section{Structured Youth Programs}

The positive benefits associated with parental involvement in the reviewed contexts should also extend to structured youth programs. However, research related to parental involvement in structured youth programs is fairly sparse (e.g., Catalano, et al., 2004; Roth, \& Brooks-Gunn, 1998). In their review, Catalano, et al. (2004) noted that many of the most effective programs intentionally targeted multiple contexts (e.g., program, school, family, etc.) and often involved parents. Parental involvement strategies included providing direct services to parents, requiring parents to participate in take-home activities, and involving parents directly in program implementation. While factors of effective youth programs identified in this study have proved an invaluable resource to researchers and practitioners, it does not provide insights into the efficacy of parental involvement in these programs. McCurdy and Daro (2001) developed an integrated theory of parental involvement that considers the multiple influences that affect familial program participation, but the scope of their work focused on family-centered rather than youth-centered programs. Research is needed that specifically looks at the involvement of parents in programs where the main target audience is the youth themselves. Additionally, this research needs to consider the impacts of involvement as well as the processes that account for many observable outcomes.

\section{Summary and Research Questions}

Given previous research and the need for additional studies of parental involvement in youth leisure contexts, this study qualitatively investigated the impacts and processes associated with parental involvement in an out-of-school program for middle and high school students. The following research questions guided the study:

1. What role does parental involvement play in the youths' experiences in the program?

2. How does parental involvement in the program influence the parent/child relationship?

3. What role does parental involvement play in terms of the program's long-term impact on youth participants?

\section{Method}

\section{Program Description}

The provider of the observed program was a non-profit organization that offers international immersion experiences for middle and high school students. The proximal goal of the program is to increase participants' knowledge and attitudes related to science, culture, leadership, and 
service with a distal goal of promoting global citizenship. The programs consist of three stages: (a) a preparatory after-school program, (b) an international field workshop, and (c) a post-trip service project. Programs are offered for a variety of international destinations (e.g., Peru, Costa Rica, Africa, etc.) and are marketed to private and public school teachers. Teachers who wish to sponsor a program recruit students from their school to participate. Travel groups range in size from 10 to 80 participants, which includes students, teachers, and parents.

After-school program. The program provides teachers with an after-school curriculum that consists of 9 to 12 sessions ranging in length from 1 to 3 hours. These lessons occur during the fall or spring prior to the group's international experience. The length of the preparatory program varies between groups-some implement multiple sessions over a few weeks whereas other groups implement one session every couple of weeks. Many of the groups also participate in additional fundraising and other preparatory activities.

International field workshop. The international portion of the program consists of a one- to two-week field workshop and usually occurs during the summer. Larger groups are divided into smaller teams for the field workshop to facilitate participation and hands-on learning. The workshop consists of experiential education focused on ecology and conservation biology as well as cultural immersion activities with the indigenous people (e.g., community service projects and cultural education). The provider coordinates all aspects of the international portion of the program (e.g., logistics, food and lodging, programming, etc.). A provider staff member accompanies each group, and additional in-country field guides facilitate the bulk of the activities and instruction.

Post-trip service project. Following the international field workshop, each group implements a service project designed to benefit their local community or a community visited during the international field workshop and build leadership abilities for the participating students.

\section{Participant Description}

Participants in this study came from a group located in a suburb of a large Midwestern city in the United States. This group was selected due to its size $(N=77)$ and teacher supportiveness. This group also was a good fit for the study's aims because it had a higher ratio of traveling parents than any other group. The group included 46 youth (18 females and 28 males) with a mean age of $13.4(S D=.65), 26$ parents (9 females and 17 males) with a mean age of 44.7 $(S D=3.78)$, and 5 teachers (3 females and 2 males) with a mean age of $43.4(S D=8.96)$. The group spent a week visiting a variety of locations within the Peruvian Amazon basin, and a smaller portion of the group took an additional week to hike the Inca Trail and visit Machu Picchu.

The group included in this study presented a unique opportunity to investigate processes associated with parental involvement because a significant portion of the youth participants' parents were heavily involved with the program. Almost half of the youth had parents who traveled with the group to the international workshop, thus providing ample opportunities for parents to play a role in their children's experiences. At the same time, contrasts could be drawn within the same group between those youth with and without traveling parents. The opportunity to travel was open to all parents but there was no concentrated effort to recruit traveling parents as the main focus of the program was on the youth. The high cost of traveling may have been prohibitive for some parents, though the study did not collect data on reasons why parents chose not to travel. 
While not required, parents had the option to take part in each component of the program including the preparatory classes, the international workshop, and the follow-up service project. Parents could also get involved with preparatory homework activities and other trip preparations (e.g., acquiring travel supplies, packing, etc.). Parents who chose to travel with a group served as chaperones. The provider required that chaperones be placed in separate field workshop teams from their participating children. This policy was developed to allow for both the participation of parents as well as the promotion of an autonomous experience for youth participants. Teams could come together at meal times and in the evenings, allowing parents and children to interact and share their experiences from the day.

\section{Data Collection}

Qualitative data collection took part as a component of a larger evaluation conducted by the principle investigator (PI) for the sponsoring organization. The Institutional Review Board (IRB) at Texas A\&M University approved all data collection protocols. Qualitative data collection involved focus groups and dyadic interviews (Table 1). Separate focus groups for youth and adult interviews occurred throughout the study. In other words, youth were not interviewed in the presence of their teachers and/or parents. Focus groups and dyadic interviews were conducted with youth participants and their parents during three three-day site visits conducted by the PI. The first two site visits occurred during the preparatory portion of the program (one during the middle and one towards the end), and a post-travel visit took place during the fall after the summer international travel experience. During each site visit, multiple student focus groups (from four to six participants) and one large parent focus group (from eight to twelve parents) were conducted. Focus groups allowed participants to share thoughts about their experiences in the program and to respond to a variety of questions designed to facilitate discussion regarding the study's research questions. Each focus group lasted anywhere from 15 to 30 minutes. The PI also observed various activities associated with the program, such as after school meetings. The follow-up visit allowed the PI to interview the same groups of individuals regarding their overall assessment of the program as well as their perceptions of the long-term impact of their experiences.

Table 1

Summary of Case Study Interviews/Focus Groups

\begin{tabular}{|l|c|c|c|c|}
\hline & $\begin{array}{c}\text { Preparatory } \\
\text { Program }\end{array}$ & $\begin{array}{c}\text { International } \\
\text { Workshop }\end{array}$ & Follow-up & Total \\
\hline Youth & 10 & 23 & 11 & 44 \\
\hline Parents & 2 & 5 & 1 & 8 \\
\hline Teachers & 3 & 1 & 1 & 5 \\
\hline Staff & --- & 2 & --- & 2 \\
\hline
\end{tabular}


The PI also conducted program observations and interviews during the group's two-week international field workshop in Peru. The first week was spent in the Peruvian Amazon basin and included activities such as wildlife observations, service projects, and learning about the local culture. The second week of the program took place in central Peru where participants hiked the Inca Trail to Machu Picchu. The entire group participated in the Amazon portion of the trip while approximately half of the group stayed for the Inca Trail portion. Interviews and focus groups were conducted with all youth, parents, teachers, and program staff members participating in the program. In addition, the PI conducted participant observations and took field notes regarding all aspects of the program. These notes were transcribed and incorporated into the analysis.

\section{Analysis Procedures}

The analysis was guided by grounded theory methodology as outlined by Strauss and Corbin (1998a) and the study's research questions. This process included reading pertinent portions of the transcripts in order to identify repeated words, phrases, and themes. Open coding enabled the development of themes that were grounded in the data themselves (Strauss, \& Corbin, 1998b). Through axial coding, commonalities between categories allowed for the development of more abstract categories under which related subcategories were grouped (Strauss, \& Corbin, 1998b). Axial coding occurred concurrently with open coding. Once fairly developed categories emerged, the researchers moved to selective coding, whereby a core category was identified and the focus of the analysis shifted to connecting other categories to this core category in order to begin the development of a grounded theory (Strauss, \& Corbin, 1998b).

The final step of the analysis involved the integration of themes and relationships between these categories relative to the study's research questions. Creswell (2007) suggests researchers employ at least two validation strategies to ensure the quality of their work; this study employed four: (a) extensive time spent in the field with the subjects, (b) the use of multiple forms of data collection (e.g., interviews with parents, teachers, staff, and youth; field notes; and open-ended survey questions), (c) member checking, and (d) peer review.

\section{Researcher's Relationship to the Data}

As noted, the PI spent time with members of the case study group as a participant observer of the program. The PI was introduced to the group during the first site visit as the external evaluator of the program who would be conducting interviews and program observations. The PI's role as an objective observer was explained and participants were invited to openly share their thoughts and opinions throughout the data collection process. The PI focused on building rapport with participants to develop relationships that would foster the open sharing of information. The PI had previous experience as a youth program director, so taking on the role of observer required a conscious effort to avoid taking a participatory position in the program. However, the PI's presence in the field still influenced the youths' experiences. For example, without the interviews and focus groups, many of the youth would not have had intentional opportunities to discuss their program experiences.

\section{Results}

The research questions addressed the impact of parental involvement on the children's experiences in a leisure-oriented enrichment program, the effects of parental involvement in the program on the parent/child relationship, and the role of parental involvement on the program's long-term impact on the children. The data dealt generally with parental involvement in the program (e.g., attending meetings, helping students prepare for travel, etc.) and dealt 
specifically with the perceived influence of traveling parents on the experience of traveling youth. The findings are organized into sections related to each research question.

\section{What Role Did Parents' Involvement in the Program Play in the Youths' Program Experience?}

The data suggest that parents did play a role in their children's program experience to varying degrees-from collaborative engagement with the sponsoring teachers to more direct involvement with their children during the program. For example, teachers frequently mentioned how they relied on the parents to make the program successful ("I can't imagine [running the program] without the parents"). Parents were asked to fill multiple roles including participating in fundraisers ("when we [the teachers] begin fundraising we say, you guys [parents] bring the resources ... you need to bring to us your expertise, your experience, your connections to help us raise funds") and acting as disciplinarians. One of the teachers explained the disciplinarian role as follows:

We rely on [parents] so much just on the spur of the moment. I mean, they don't technically have a duty-you know, we inform them that they're kind of a link in the chain, you know. If they're in a small group and some kid is doing something they probably shouldn't, we tell them, you know, just quietly say a little something to them and refocus them or whatever they need.

Sponsoring the international immersion program required teachers to take on numerous responsibilities in addition to their regular teaching duties. Parental involvement helped ease this burden. Additionally, teachers felt that if they were able to get parents to buy into the program, it would enhance the experience for their kids. One youth noted: "If the parent . . . knows what we're doing and listens to us and understands kind of what our goals are, they can reinforce that at home and then the kid is more apt to get more out of the experience." Teachers did report that some parents caused problems. As one teacher put it, "they badger you at meetings," but these instances seemed to be the exception. Based upon teachers' comments, it is clear that the program would not be the same without the parents.

For some of the youth, their parents played a major role, beyond merely financing the experience, during both the preparatory program and international workshop. Youth perceived parental involvement to have a variety of both positive and negative consequences. For example, youth with involved parents noted a variety of ways their parents supported them during the program. Examples of such assistance included fundraising support ("Mom helped me write a letter to her boss so I could get a donation from the company that they worked at"), program-related homework help ("We talk about all the things I learn in the meetings, [my parents] help me so that I understand my homework $\mathrm{ok}^{\prime \prime}$ ), and emotional support ("My parents provided mental support in the pressure that you have to prepare and all that stuff").

Conversely, a number of the youth who did not have parents travel with them on the international workshop noted the experience, without parents, promoted their sense of independence. As one participant stated:

And I think being away from home and my family and put in this totally different environment has definitely made me stronger and kind of showed me that I can do this. I have really gained a lot of confidence, I think, because I am usually, you know, with my parents or my best friends or whatever, and I was kind of put in a group that I did not have any close friends or anything so [I] kind of had to make friends. 
In an effort to promote opportunities for independence, even for youth with traveling parents, the program enforces a rule whereby youth and their parents do not participate directly together in most portions of the workshop. For example, parents and children are never placed within the same groups or teams during the international workshop. The adult leaders of the case study group expressed support for this policy as it appeared to promote independence:

The way we set it up is we don't put parents in the same group, that's a [program provider] request and that's one of the best things to do because then she really doesn't have to go is it ok to do that Dad? You know that kind of a thing, and that's really important for them to really stretch out and kind of experience it for themselves.

Even with the intentional separation of parents from their children, some youth expressed a perceived lack of independence associated with having a parent travel with the group. One male youth expressed his frustration at having to watch out for his mom and stated that he would have preferred to have come on his own. While this sentiment highlights a potentially negative aspect of parental involvement, it was one of the only negative parental involvement comments from youth. Interestingly enough, a few days after expressing dissatisfaction with the presence of his mom on the trip, the same youth had an experience that may have modified his view about the value of parental involvement. While hiking on the Inca Trail in one of the steeper portions of the trail, this youth found his mother needed his support to successfully complete the hike. He had the following to say about the experience:

I feel like the biggest, most important thing I learned today was that helping somebody else's experience could end up helping yours in the end. Because I stayed back with my mom today, and I know that she appreciated it a lot because me and [two other youth] all kept supporting her and tell[ing] her to keep going, and I know that it meant a lot to her, and in the end it made me feel like I had really changed her experience.

This quote also indicates that, at least for this mother/son pair, parental involvement in the program impacted the parent/child relationship in a variety of ways, which is the topic of the study's next research question.

\section{How Did Parental Involvement in the Program Influence the Parent/Child Relationship?}

Parent and youth comments suggested that having a parent involved in the program enriched the parent/child relationship. While this statement appears to apply more strongly to parents who participated in the international workshop, relationships were also impacted during the program's preparatory phase. For example, a number of students reported that the involvement of their parents in the preparatory program fostered increased positive family interactions. One male participant explained that in order to prepare for the Inca Trail he had begun exercising ("We are getting out and riding bikes together to prep me for the trail") and that this activity had a variety of spillover effects as the following conversation illustrates:

PI: Ok. So you are exercising as a family?

YOUTH: Yeah .... We like to ride down to the gas station, we like to hang out and talk as we go. We are starting to eat dinner on the table more than [in front of] the TV. We talk about like how each day went, we play more games together.

PI: So how is that related to [the program]? 
YOUTH: I don't know, there are just some connections I have made since we started exercising as a family; more things have started to connect together, playing games.

Even parents reported that preparing for the program provided extra opportunities to interact with their children. One father noted:

The nice thing is, you know, we study this together, and we do our homework and stuff- Or, you know, and so we'll be driving along and we'll just be talking about something in the car rain forest related, and I think if I weren't experiencing this [program], this conversation wouldn't be taking place.

Involvement in the program seems to have provided some youth and their parents a variety of experiences that impacted their relationships. Three categories of impacts were identified: (a) communication between parent and child, (b) parent/child bonding, and (c) parent's and child's perceptions of one another.

Parent/child communication. Both, parents and youth expressed the perception that participation in the program provided them a common topic of conversation. At an age when common ground may be hard to find between early adolescents and their parents, this program helped youth and parents to experience positive changes in their ability to communicate with each other. One male participant expressed this sentiment as follows: "I really think that me and my dad have gotten, like, a lot closer just like because we have this common experience that we can talk about, and just, like, it gives us more of an excuse, I guess, to talk to each other." A father made a similar comment: "I gained a common topic to talk about when we go back [home] -for many months we will be able to recall our travels. It opens communication channels."

Parent/child bonding. These shared experiences and open communication channels appeared to lead, in part, to some youth and parents experiencing the development of stronger relational bonds. One mother stated, "I actually gained a closeness/bond to [my son] that we did not have before and that was enhanced by this journey." As evidenced by this youth's statement, youth/traveling parent bonds appeared to strengthen even with the separate parent/child rule:

We probably would not have bonded that much, like, we are really close now; like, we probably would not have been that close if we would not have gone on that trip and shared those experiences, even though we were not in the same group.

The influence these bonds had on trip dynamics was observed by the PI as the group prepared for its first night on the Inca Trail. When tents were handed out at the trailhead camp and the group was instructed to select tent partners, the youth with traveling parents uniformly made the choice to share tents with their parents. The willingness with which this happened impressed the teachers: "We [the teachers] thought it was really interesting that last time when we did the tents all the kids wanted to tent with their parents. . . . I think that speaks [to] the parents' and the kids' relationships."

Parent/child perceptions. Additionally, the experience placed parents and youth into a new context that fostered, for some participants, the development of new perspectives and understandings of each other. One male youth made the following comment related to this idea of new perspectives about his father: 
I have learned a lot more about him just like as a person, I guess because I saw him, like, in a different light; like where he is not the authority, I guess. So he was learning just like I was, and we were on the same kind of a level for a little bit, and I guess that opened him a little more. We are a lot closer than we used to be, I really think we are.

Through their joint participation in novel contexts provided by the program, this youth began to view his father as more than just an authority figure. A new level of equality appeared to enter their relationship. Similar perspective shifts were also noted by some of the traveling parents. For example, one adult commented that over the course of the trip, "you can see [the youth participants] starting to grow up."

\section{What Role Did Parental Involvement Play in Terms of the Program's Long-Term Impact on Youth Participants? \\ During the follow-up visit, many of the youth voiced frustrations that they could not fully explain the magnitude and importance of what they had experienced. One youth said, "There is so much you want to tell them [peers], and they don't understand." Although some youth noted that having lots of pictures helped them tell people about their experience, it was still hard to get across what the experience meant to them:}

When people ask you, like, "How was your trip?" it's hard to say, "Oh, this day we went fishing, and this day we did that." It's hard to tell them, to make them understand what it really was. Because it was so much greater than just a trip we went on.

Adults also mentioned inherent shortcomings associated with telling people who were not there about the experience: "We can show them the pictures and give a brief explanation, but they don't know the depths of how we have changed by explaining to them what we saw. They only see only visual, they don't know the internal." There was also mention of disconnect within families between travelers and non-travelers. For example, one father who traveled noted, "I think for us the toughest part was my son that did not go. So for a little while [my son who traveled] and I would just be going on and on about this trip, and [the son who did not attend] would be mad, sitting there and be like 'You guys about done?"' In response to this comment another father stated, "My wife has made comments like that. She wishes she had gone on the trip just to feel part of those conversations . . . but clearly . . . you are left out when you have not experienced [the program]."

These difficulties communicating the experience to others were alleviated, in part, for those students who had parents travel with the group. Some students noted that they appreciated having someone right in their family who they had shared the experience with and with whom they could reminisce. In talking about his father, a youth commented:

I really talked to him [his father] more than like a lot of other people like about my trip . . . because, like, he gets it, I guess. It's really hard to explain like the actual feelings and stuff and actual experience that you have to people who just don't have a clue really.

Thus it appears that having a parent who traveled with the group allowed these youth easy access to someone who could validate and understand experiences associated with the program in ways non-travelers could not. 


\section{Discussion}

The findings suggest that parental involvement is associated with a number of outcomes and processes. Although some negative experiences occurred between youth and parents involved in the program, the majority of interactions appeared to be either neutral or positive. This may be partly attributed to the fact that parents were not placed in positions of authority over their own children. Although the youth often commented on their frustrations with the teachers and other adults in the program, they rarely if ever directed these feelings towards their own parents. While some youth at times felt having a parent travel with the group constrained their independence, the intentional separation of parents and youth during portions of the program allowed both groups to have autonomous experiences.

Many of the parents and youth reported that their experiences in the program improved parent/child communication, parent/child bonding, and parents' and children's perceptions of one another. It appears the program provided traveling parents and youth a shared experience that allowed them common ground to build their relationships. This finding aligns with previous research related to shared experiences between youth and parents that suggests these experiences increased parents' empathy for and understanding of their children's experiences (Green, \& Chalip, 1997; Holt, Tamminen, Black, Sehn, \& Wall, 2008). This possibility presents an interesting avenue for future research about the potential benefits of parent/adolescent shared experiences. At a time in life when many parents may struggle to find common ground with their adolescent children, structured recreation experiences may provide them the opportunity to find common ground. Future research should investigate what programs can do to most effectively facilitate positive shared experiences between youth and parents.

As previously noted, follow-up interviews indicated that having a parent travel with the group provided some youth with an individual who they could talk to after returning home. One frequent critique of short-term programs for youth is that their impact quickly dissipates after participation ends. This may be due, in part, to difficulties participants face when attempting to convey their program experience to non-participating peers and family members. As was noted, a number of youth expressed frustrations about difficulties conveying their experiences to friends and family members who did not travel with them.

The possible post-participation impact of parental involvement during the program may be partially explained with insights from Bronfenbrenner's ecological systems theory (1979; 1998). Bronfenbrenner suggests that each individual inhabits a series of nested contexts starting at the intrapersonal level and proceeding towards larger community and social levels. He also suggests that learning transfers more successfully between contexts when individuals have connections with others who inhabit both contexts. Accordingly, it may be that the impact of a program has a better chance of transferring to a participant's home context if someone from that context also participates in the program. This individual can then serve as a transition agent who helps facilitate the transfer of the experience outcomes back to the home context. This assumption appears to be partially born out in this study's findings and deserves additional attention in future research.

\section{Limitations}

This study represents an exploratory effort to understand the processes and impact associated with parental involvement in a structured youth program. While the program provided a unique opportunity to observe processes associated with parental involvement in a youth program 
setting, the data were drawn from a self-selected sample of youth and parents. The youth in the study had chosen to take part in the program, and the parents had chosen to engage in various forms of involvement from participating in the preparatory program to actually traveling with the group. The nature of the sample makes it unwise to generalize these findings beyond the scope of this program. While the study attempts to identify processes and impacts of parental involvement, the findings may be quite different with a more diverse and random sample. Additional qualitative and quantitative research is needed to further address the impact of parental involvement in structured programs with a potentially less biased sample.

It can also be argued that sample members may have felt pressure to provide desirable responses in order to protect the program. To address this potential concern, the role of the PI and the evaluation as a whole was openly explained to all participants, and the importance of providing truthful and open feedback was highlighted on multiple occasions. Additionally, since data collection occurred for almost a year, the PI had the opportunity to develop relationships with the sample members, which hopefully encouraged sincere responses during interviews and focus groups.

\section{Implications for Practice}

Although from a practitioner's perspective not including parents in youth programs and just focusing on the youth participants may seem easier or preferable, findings from this study suggest programs that engage in such an approach may miss out on potential benefits associated with parental involvement. It may be that parents can play the role of transition agent and help their child more effectively transfer positive outcomes from a program back into the home environment. That being said, the involvement of parents needs to be intentional. For example, in the observed program the decision was made to put traveling parents in separate teams from their own children in order to allow the youth to still experience a degree of independence while traveling. This decision appears to have addressed practitioners' concerns about over-involved parents while still allowing parents to share in the same experiences as their children. Additional research looking at the ability of structured recreation programs to provide positive shared experiences between youth and adults suggests it is important for practitioners to provide adults involved in the program (in this case parents) with clear roles and expectations in order to best facilitate their involvement and avoid having parents simply fall into the role of extra adult disciplinarians (Duerden, \& Witt, 2010).

Given the suggested potential benefits associated with youth and parents conversing about the experience after their participation in the program ends, programs should also consider ways to facilitate these interactions. This could be accomplished by providing participants with postparticipation debriefing sheets that provide parents and youth with talking points to help them discuss the experience with each other. Participants could also be contacted through mail or email after the program ends with similar reflection prompts designed to stimulate discussion between youth and their parents.

\section{Conclusion}

While parental involvement has been promoted as a youth program best practice (Eccles, \& Harold, 1993; Trotman, 2001), details regarding its effective implementation and potential impacts have not been as well explored. The findings from this study provide insights into the processes and outcomes that may occur when parents become involved in a youth leisure enrichment program context. In the observed program, leaders noted the primarily beneficial involvement of parents as evidenced by extra support leaders received from parents who 
actively participating in the program. Parental involvement also seems to have provided parents and children a common ground experience that promoted increased parent/child communication and bonding, and altered parents' and children's perceptions of one another. Most interesting is the finding that parental involvement may actually increase the postparticipation impact of a program. Future research should consider employing an ecological systems theory approach to further investigate the relationship between parental involvement and the long-term impacts of a program.

It is well established that parents can have both negative and positive impacts their children's development. Structured leisure enrichment youth programs may be a prime context for parents and children to build positive and supportive relationships. The findings from this study suggest that parental involvement can provide a number of benefits to program participants. The enhancement of program impacts post-participation but future research is needed to more fully understand how best to involve parents in program settings.

Acknowledgements: This study was supported in part from funding through the Elda K. Bradberry Recreation and Youth Development Chair at Texas A\&M University.

\section{References}

Auerbach, C.F., \& Silverstein, L.B. (2003). Qualitative data: An introduction to coding and analysis. New York: New York University Press.

Baumrind, D. (1991). Effective parenting during the early adolescent transition. In P.A. Cowan \& M. Hetherington (Eds.). Family transitions (pp. 111-163). Hillsdale, NJ: Lawrence Erlbaum.

Benard, B. (1991). Fostering resiliency in kids: Protective factors in the family, school, and community. Portland, OR: Western Regional Center for Drug-Free Schools and Communities.

Bronfenbrenner, U. (1979). The ecology of human development. Cambridge, MA: Harvard University Press.

Bronfenbrenner, U., \& Morris, P. A. (1998). The ecology of developmental processes. In W. Damon (Ed.). Handbook of child psychology (pp. 993-1028). New York, NY: Wiley.

Brown, B.B., Mounts, N., Lamborn, S.D., \& Steinberg, L. (1993). Parenting practices and peer group affiliation in adolescence. Child Development, 64(2), 467-482. doi: 10.1111/j.14678624.1993.tb02922.x

Caldwell, L.L., \& Darling, N. (1999). Leisure context, parental control, and resistance to peer pressure as predictors of adolescent partying and substance use: An ecological perspective. Journal of Leisure Research, 31(1), 57-77.

Catalano, R.F., Berglund, M.L., Ryan, J.A.M., Lonczak, H.S., \& Hawkins, J.D. (2004). Positive youth development in the United States: Research findings on evaluations of positive youth development programs. Annals of the American Academy of Political and Social Science, 591, 98-124. doi: $10.1177 / 0002716203260102$ 
Coie, J.D., Watt, N.F., West, S.G., Hawkins, J.D., Asarnow, J.R., Markman, H.J., Long, B. (1993). The science of prevention: A conceptual framework and some directions for a national research program. American Psychologist, 48(10), 1013-1022. doi: 10.1037/0003066X.48.10.1013

Cotton, K., \& Wikelund, K.R. (2001). Parental involvement in education. Retrieved from Northwest Regional Educational Laboratory website: http://www.nwrel.org/scpd/sirs/3/cu6.html

Coulton, C., \& Irwin, M. (2009). Parental and community level correlates of participation in outof-school activities among children living in low income neighborhoods. Children and Youth Services Review, 31(3), 300-308. doi: 10.1016/j.childyouth.2008.08.003

Creswell, J.W. (2007). Qualitative inquiry \& research design: Choosing among five approaches (2nd ed.). Thousand Oaks, CA: Sage.

DuBois, D.L., Holloway, B.E., Valentine, J.C., \& Cooper, H. (2002). Effectiveness of mentoring programs for youth: A meta-analytic review. American Journal of Community Psychology, 30(2), 157-197. doi: 10.1023/A:1014628810714

Duerden, M.D., \& Witt, P.A. (2010). The impact of socialization on youth program outcomes: A social development model perspective. Leisure Sciences, 32(4), 299-317.

Eccles, J.S., \& Harold, R.D. (1993). Parent-school involvement during the early adolescent years. Teachers College Record, 94(3), 568-587.

Fletcher, A.C., Elder, J.G.H., \& Mekos, D. (2000). Parental influences on adolescent involvement in community activities. Journal of Research on Adolescence, 10(1), 29-48. doi:

10.1207/SJRA1001_2

Green, B.C., \& Chalip, L. (1997). Enduring involvement in youth soccer: The socialization of parent and child. Journal of Leisure Research, 29(1).

Green, B.C., \& Chalip, L. (1998). Antecedents and consequences of parental purchase decision involvement in youth sport. Leisure Sciences, 20(2), 95-110.

Grossman, J.B., \& Johnson, A. (1999). Assessing the effectiveness of mentoring programs. Philadelphia, PA: Public/Private Ventures.

Hill, N.E., Castellino, D.R., Lansford, J.E., Nowlin, P., Dodge, K.A., Bates, J.E., \& Pettit, G.S. (2004). Parent academic involvement as related to school behavior, achievement, and aspirations: Demographic variations across adolescence. Child Development, 75(5), 1491-1509. doi: $10.1111 / j .1467-8624.2004 .00753 . x$

Holt, N.L., Tamminen, K.A., Black, D.E., Sehn, Z.L., \& Wall, M.P. (2008). Parental involvement in competitive youth sport settings. Psychology of Sport and Exercise, 9(5), 663-685. doi: 10.1016/j.psychsport.2007.08.001

Hoyle, R.H., \& Leff, S.S. (1997). The role of parental involvement in youth sport participation and performance. Adolescence, 32(125). 
Huff, C., Widmer, M.A., McCoy, J.K., \& Hill, B. (2003). The Influence of challenging outdoor recreation on parent-adolescent communication. Therapeutic Recreation Journal, 3入1), 18-37.

Hughes, J.N., \& Kwok, O.M. (2007). Influence of student-teacher and parent-teacher relationships on lower achieving readers' engagement and achievement in the primary grades. Journal of Educational Psychology, 99(1), 39-51. doi: 10.1037/0022-0663.99.1.39

Hunter, J.P., \& Csikszentmihalyi, M. (2003). The positive psychology of interested adolescents. Journal of Youth and Adolescence, 32(1), 27-35. doi: 10.1023/A:1021028306392

Jeynes, W.H. (2007). The relationship between parental involvement and urban secondary school student academic achievement: A meta-analysis. Urban Education, 42(1), 82-110. doi: $10.1177 / 0042085906293818$

Ladd, G.W., \& Le Sieur, K.D. (1995). Parent's and children's peer relationships. In M.H. Bornstein (Ed.). Handbook of Parenting, (Vol. 4, pp. 377-409). Mahwah, NJ: Lawrence Erlbaum Associates.

Larson, R.W. (2000). Toward a psychology of positive youth development. American Psychologist, 55(1), 170. doi: 10.1037//0003-066X,55.1.170

Mahoney, J.L., \& Stattin, H. (2000). Leisure activities and adolescent antisocial behavior: The role of structure and social context. Journal of Adolescence, 23(2), 113-127. doi: 10.1006/jado.2000.0302

Marcia, J. E. (1980). Identity in adolescence. In J. Adelson (Ed.), Handbook of adolescent psychology (pp. 159-187). New York: Wiley.

McCurdy, K., \& Daro, D. (2001). Parent involvement in family support programs: An integrated theory. Family Relations, 50(2), 113-121. doi: 10.1111/j.1741-3729.2001.00113.x

Outley, C.W., \& Floyd, M.F. (2002). The home they live in: Inner city children's views on the influence of parenting strategies on their leisure behavior. Leisure Sciences, 24(2), 161-179.

Pelletier, L.G., Fortier, M.S., Vallerand, R.J., \& Briere, N.M. (2001). Associations among perceived autonomy support, forms of self-regulation, and persistence: A prospective study. Motivation \& Emotion, 25(4), 279-306. doi: 10.1023/A:1014805132406

Rogers, M., Wiener, J., Marton, I., \& Tannock, R. (2009). Supportive and controlling parental involvement as predictors of children's academic achievement: Relations to children's ADHD symptoms and parenting stress. School Mental Health, 1(2), 89-102. doi: 10.1007/s12310-0099010-0

Roth, J., \& Brooks-Gunn, J. (1998). Promoting healthy adolescents: Synthesis of youth development program evaluations. Journal of Research on Adolescence, 8(4), 423-459.

Scales, P.C., Benson, P.L., Leffert, N., \& Blyth, D.A. (2000). Contribution of developmental assets to the prediction of thriving among adolescents. Applied Developmental Science, $4(1)$, 27-46. doi: 10.1207/S1532480XADS0401_3 
Schmitt-Rodermund, E., \& Vondracek, F.W. (1999). Breadth of interests, exploration, and identity development in adolescence. Journal of Vocational Behavior, 55(3), 298-317. doi: $10.1006 /$ jvbe. 1999.1683

Shaw, S.M., \& Dawson, D. (2001). Purposive leisure: Examining parental discourses on family activities. Leisure Sciences, 23, 217-231. doi: 10.1080/01490400152809098

Smoll, F.L., Smith, R.E., Barnett, N.P., \& Everett, J.J. (1993). Enhancement of children's selfesteem through social support training for youth sport coaches. Journal of Applied Psychology, 78(4), 602-610. doi: 10.1037/0021-9010.78.4.602

Strauss, A., \& Corbin, J. (1998a). Basics of qualitative research (2nd ed.). Thousand Oaks, CA: Sage Publications.

Strauss, A., \& Corbin, J. (1998b). Grounded theory methodology: An overview. In N.K. Denzin \& Y.S. Lincoln (Eds.). Strategies of qualitative inquiry (Vol. II, pp. 158-183). Thousand Oaks, CA: Sage.

Trotman, M.F. (2001). Involving the African American parent: Recommendations to increase the level of parent involvement within African American families. Journal of Negro Education, 70(4), 275-285.

U.S. Department of Education. (1994). Strong families, strong schools: Building community partnerships for learning. Washington, DC: US Government Printing Office.

Wells, S.M., Widmer, M.A., \& McCoy, J.K. (2004). Grubs and grasshoppers: Challenge-based recreation and the collective efficacy of families with at-risk youth. Family Relations, 53(3), 326333. doi: 10.1111/j.0197-6664.2003.0009.x

Witt, P.A., \& Caldwell, L.L. (2005). 10 principles of youth development. In P.A. Witt \& L.L. Caldwell (Eds.). Recreation and Youth Development (pp. 3-23). State College, PA: Venture Publishing.

Woolley, M.E., \& Grogan-Kaylor, A. (2006). Protective family factors in the context of neighborhood: Promoting positive school outcomes. Family Relations, 55(1), 93-104. doi: doi:10.1111/j.1741-3729.2006.00359.x

Wylleman, P., DeKnop, P., Ewing, M.E., \& Cummings, S.P. (2000). Transitions in youth sport: A developmental perspective on parental involvement. In D. Lavallee \& P. Wylleman (Eds.), Career transitions in sport: International perspectives (pp. 143-160). Morgantown, WV: Fitness Information Technology, Inc.

Zabriskie, R.B., \& McCormick, B.P. (2001). The Influences of Family Leisure Patterns on Perceptions of Family Functioning. Family Relations, 50(3), 281-289. doi: 10.1111/j.17413729.2001.00281.x

(C) Copyright of Journal of Youth Development Bridging Research and Practice. Content may not be copied or emailed to multiple sites or posted to a listserv without copyright holder's express written permission. Contact Editor at: patricia.dawson@oregonstate.edu for details. However, users may print, download or email articles for individual use.

ISSN 2325-4009 (Print); ISSN 2325-4017 (Online) 